\title{
A bibliometric analysis of global research output on network meta-analysis
}

\author{
Jiyuan Shi ${ }^{1 \dagger}$, Ya Gao ${ }^{2 \dagger}$, Liu Ming ${ }^{2}$, Kelu Yang ${ }^{1}$, Yue Sun ${ }^{3}$, Ji Chen ${ }^{4}$, Shuzhen Shi ${ }^{2}$, Jie Geng ${ }^{5}$, Lun Li $i^{6}$, Jiarui Wu ${ }^{7}$ and
} Jinhui $\operatorname{Tian}^{1,2,8^{*}}$ (1)

\begin{abstract}
Background: Network meta-analysis (NMA) has been widely used in the field of medicine and health, but the research topics and development trends are still unclear. This study aimed to identify the cooperation of countries and institutes and explore the hot topics and future prospects in the field of NMA.

Methods: Data of publications were downloaded from the Web of Science Core Collection. We used CiteSpace V, HistCite 2.1, and Excel 2016 to analyze literature information, including years, journals, countries, institutes, authors, keywords, and co-cited references.

Results: NMA research developed gradually before 2010 and rapidly in the following years. 2846 NMA studies were published in 771 journals in six languages. The PLoS One (110,3.9\%) was the most productive journal, and N Engl J Med (5904 co-citations) was the most co-cited journal. The most productive country was the United States (889, 31\%) and the most productive institute was the University of Bristol (113,4.0\%). The active collaborations were observed between developed countries and between productive institutes. Of the top 10 authors, four were from the UK, and among the top 10 co-cited authors, six were from the UK. Randomized evidence, oral anti-diabetic drugs, coronary artery bypass, certolizumab pegol, non-valvular atrial fibrillation, and second-line antihyperglycemic therapy were the hot topics in this field.

Conclusions: NMA studies have significantly increased over the past decade, especially from 2015 to 2017. Compared with developing countries, developed countries have contributed more to these publications and have closer cooperation, indicating that cooperation between developed and developing countries should be further strengthened. The treatment of diabetes, cardiovascular diseases, and immune rheumatism are the main hot topics.
\end{abstract}

Keywords: Bibliometric analysis, Network meta-analyses, Development trends, Hotspots, Web of Science, CiteSpace

\section{Background}

Network meta-analysis (NMA), also known as mixed treatment comparisons, is an extension of the pairwise meta-analysis method for integrating data from trials to compare at least two competing healthcare interventions [1-4]. Compared with traditional meta-analysis, NMAs

\footnotetext{
*Correspondence: tjh996@163.com

†jiyuan Shi and Ya Gao contributed equally to this work.

${ }^{2}$ Evidence-Based Medicine Center, School of Basic Medical Sciences, Lanzhou University, Lanzhou City, China

Full list of author information is available at the end of the article
}

allow for the synthesis and comparison of evidence from multiple interventions, including direct and indirect evidence, to provide more accurate estimates of treatment outcomes, even though head-to-head trials may be lacking [5-7]. NMAs can also generate a relative ranking of all interventions related to the outcome to provide valuable information for patients, practitioners, and decisionmakers $[8,9]$. Because of the many advantages of NMA, scholars' interest in this method has gradually increased, and it has been widely used in the field of medicine and health $[2,10]$. 
Bibliometric analysis is a statistical method of bibliographic counting that can assess and quantify the literature growth of a particular research content [11]. Bibliometric methods can extract and analyze the characteristics of publications including years, journals, authors, countries, and keywords to provide development trends or future research orientations of a specific subject $[12,13]$, which can help scholars grasp the development characteristics of the field and guide their future research [14]. In recent years, there have been a lot of studies in various fields that were published using this method. Li et al. [15] analyzed the international collaborations and academic relationships on haze research. Ruiz-Real et al. [16] identified the development trends and future research initiatives in the field of circular economy and environment. Gimenez-Espert and PradoGasco [17] analyzed the evolution of and current status of six nursing journals and presented the most cited articles, co-citations, and co-authors. Liang et al. [18] demonstrated the status quo, intellectual base, and hot topics in the field of medication literacy. There also has been a study published in 2015 that analyzed the global research collaboration of NMA using social network analysis methods [19]; however, this research did not analyze the co-cited journals, co-cited authors, co-cited references, and research hotspots. Besides, the number of NMAs has increased significantly in recent years, and global research cooperation may have changed. Therefore, it is necessary to analyze the current status of NMA research through bibliometric methods.

This study aimed to (1) analyze the distribution of publication outputs, journals, countries, institutes, authors, keywords, and references on NMA research; (2) identify the cooperation of countries and institutes; (3) and explore the development dynamics and existing hot topics.

\section{Methods}

\section{Data source and search strategy}

The Web of Science (WoS) Core Collection was retrieved to obtain relevant NMAs from inception to December 2018. The search strategy: TS $=$ ("network meta analysis" OR "network meta analyses" OR "network metaanalysis" OR "network meta-analyses" OR "network metaanalyses" OR "network metaanalysis" OR "mixed treatment comparison meta analysis" OR "mixed treatment comparisons meta analyses" OR "mixed treatment meta analysis" OR "mixed treatment meta analyses" OR "mixed treatment comparison meta-analysis" OR "mixed treatment comparisons meta-analyses" OR "mixed treatment meta-analysis" OR "mixed treatment meta-analyses" OR "mixed treatment comparison metaanalysis" OR "mixed treatment comparisons metaanalyses" OR "mixed treatment metaanalysis" OR "mixed treatment metaanalyses" OR "multiple treatment comparison meta analysis" OR "multiple treatment comparisons meta analyses" OR "multiple treatments meta analysis" OR "multiple treatments meta analyses" OR "multiple treatment meta analysis" OR "multiple treatment meta analyses" OR "multiple treatment comparison meta-analysis" OR "multiple treatment comparisons meta-analyses" OR "multiple treatments meta-analysis" OR "multiple treatments meta-analyses" OR "multiple treatment metaanalysis" OR "multiple treatment meta-analyses" OR "multiple treatment comparison metaanalysis" OR "multiple treatment comparisons metaanalyses" OR "multiple treatments metaanalysis" OR "multiple treatments metaanalyses" OR "multiple treatment metaanalysis"); index: (SCI-EXPANDED). In the present study, only article and review papers were included. All searches were done within the same day to avoid the bias caused by the daily database updates. There were no restrictions on language, data category, and publication year.

\section{Statistical analysis}

We used HistCite 2.1 (HistCite Software LLC, New York, USA) and CiteSpace V (Drexel University, Philadelphia, PA, USA) to analyze publication characteristics, including publication languages, years, journal sources, co-cited journals, countries, institutes, authors, co-cited authors, co-cited references, and keywords. Excel 2016 (Redmond, WA, USA) was used to analyze the publication trend. The three-term polynomial (Trinomial model) was applied to forecast the growth of publications in the following year [14]. We used CiteSpace V software to evaluate the relationships among the high-yield countries, institutes, and high-frequency keywords [20], and generate visual network maps for countries, institutions, and keywords. In the visual network maps, nodes represent the analytical characteristics, such as countries, institutes, and keywords, and the links between nodes reflect the co-operation, co-occurrence, or co-citation [21-24]. The size of the nodes reflects the number of publications or frequency, and the different colors of nodes and lines represent different times [25]. Purple circles represent centrality, and nodes with a larger centrality are often seen as key points in the network [18, 22]. We also performed cluster analysis for keywords and all clusters were named according to the terms extracted from the articles. Furthermore, we identified references with strong citation bursts through CiteSpace V.

The parameters of CiteSpace were as follows: time slicing (2002-2018), years per slice (1), term source (all selection), node type (choose one at a time), selection criteria (30), pruning (none), and visualization (cluster view-static, show merged network). 


\section{Results}

\section{Publication language}

A total of 2846 articles were included (Fig. 1), which were published in six languages. Among the 2846 articles, 2821 (99\%) were published in English, 11 published in Spanish, 6 published in German, 5 published in French, 2 published in Polish, and 1 published in Russian.

\section{Publication outputs}

The first paper of included NMA research was published in 2002, and the NMA research developed gradually before 2010 and rapidly in the following years. As shown in Fig. 2, the number of publications per year was less than 10 before 2009. After 2010, the number of articles increased rapidly and broke through 200 articles in 2014, 500 articles in 2016, and 600 articles in 2017. Among them, the growth rate from 2015 to 2017 was the fastest and increased from 362 (13\%) in 2015 to 690 (24\%) in 2017. From 2013 to 2018, 2610 articles were published, accounting for $92 \%$ of all the included studies. The three-term polynomial model was used to evaluate the relationship between the number of publications and the year (excluding the data for 2018). It was found that the polynomial curve fits well with the

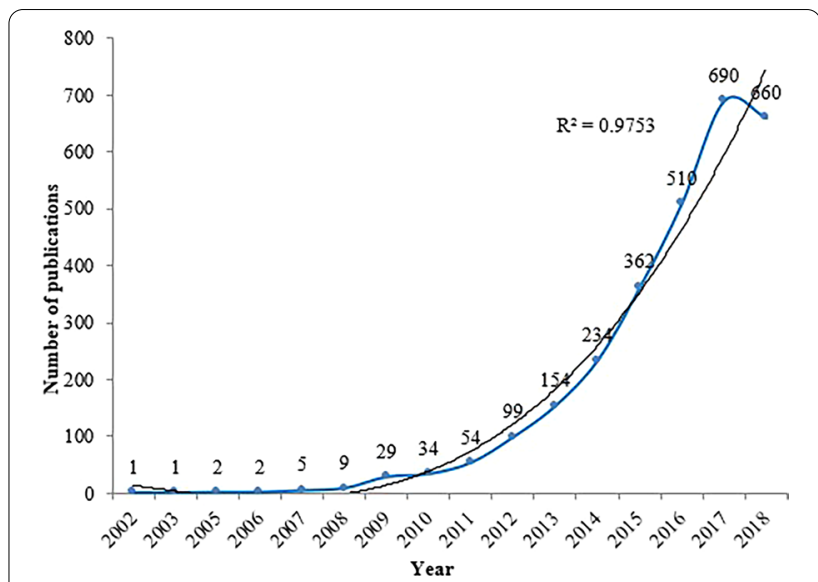

Fig. 2 Publication years and growth forecast for NMA research

annual literature growth trend with a high coefficient of determination $\left(\mathrm{R}^{2}=0.9753\right)$. By the fitting curve, we can predict that the annual articles will continue to grow in the coming years.
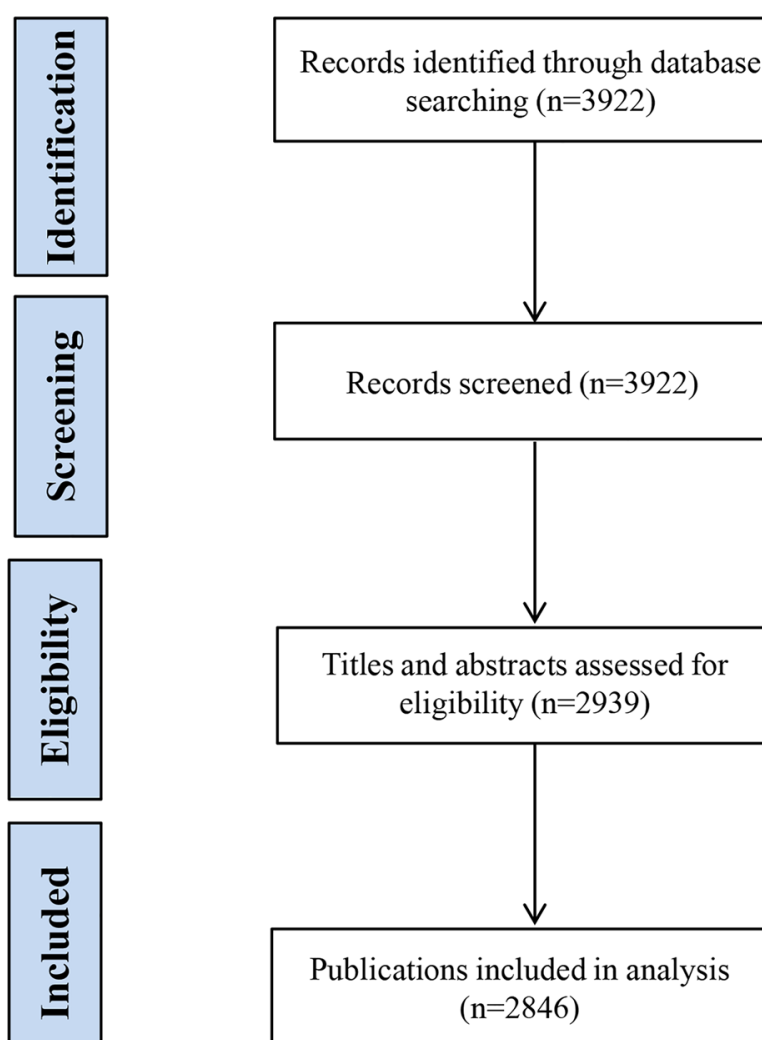

Fig. 1 The flowchart of the screening process 


\section{Journals and co-cited journals}

In total, 771 journals published articles in NMA research. Table 1 presented the top 10 journals and co-cited journals in NMA research. The journal with the largest number of publications was PLoS One (110, 3.9\%), followed by Medicine (85, 3.0\%), BMJ Open (78, 2.7\%), and Cochrane Database Syst Rev (68, 2.4\%). Of the top 10 journals, three were from the United States (USA), seven from the United Kingdom (UK), and the impact factors of seven journals were lower than 4.500. $\mathrm{N} \mathrm{Engl} \mathrm{J} \mathrm{Med} \mathrm{was} \mathrm{the}$ most co-cited journal, with 5904 co-citations, followed by Lancet (4888 co-citations), Stat Med (3696 co-citations), J Am Coll Cardiol (3101 co-citations), and Circulation (2666 co-citations). Among the top 10 co-cited journals, $50 \%$ are from the UK, and 50\% from the USA, and seven journals with the impact factors higher than 15.000 , three journals with the impact factors higher than 45.000 .
Figure 3 showed the dual-map overlay of journals. The yellow, green, and purple spline waves represent citations made by the source articles. Each spline curve starts with the citing map on the left and points to the cited map on the right. The label represented the subject covered by the journal [26]. In the current map, there were two main citation paths.

\section{Countries and institutes}

We reclassified articles from England, Scotland, Northern Ireland, and Wales to the UK and articles from Hong Kong, Macau, and Taiwan to China. In total, 85 countries involved in the publication of NMA research, and the USA $(889,31 \%)$ published the most articles, followed by China (740, 26\%), UK (708, 25\%), Canada (327, $11 \%)$, and the remaining countries published articles less than 300, Table 2. There were 43 nodes and 206 links

Table 1 The top 10 journals and co-cited journals in NMA research [n (\%)]

\begin{tabular}{|c|c|c|c|c|c|c|c|c|}
\hline Rank & Journal & $\mathrm{N}(\%)$ & Country & IF (2018) & Co-cited journal & Co-citation & Country & IF (2018) \\
\hline 1 & PLoS One & $110(3.9 \%)$ & USA & 2.766 & N Engl J Med & 5904 & USA & 70.670 \\
\hline 2 & Medicine & $85(3.0 \%)$ & USA & 1.870 & Lancet & 4888 & UK & 59.102 \\
\hline 3 & BMJ Open & $78(2.7 \%)$ & UK & 2.376 & Stat Med & 3696 & UK & 1.847 \\
\hline 4 & Cochrane Database Syst Rev & $68(2.4 \%)$ & UK & 7.755 & J Am Coll Cardiol & 3101 & USA & 18.639 \\
\hline 5 & Oncotarget & $63(2.2 \%)$ & USA & Non-SCl & Circulation & 2666 & USA & 23.054 \\
\hline 6 & Sci Rep & $45(1.6 \%)$ & UK & 4.011 & $\mathrm{BMJ}$ & 2610 & UK & 27.604 \\
\hline 7 & Res Synth Methods & $44(1.6 \%)$ & UK & 5.043 & J Clin Epidemiol & 2325 & UK & 4.650 \\
\hline 8 & BMJ & $43(1.5 \%)$ & UK & 27.604 & JAMA & 2267 & USA & 51.273 \\
\hline 9 & Curr Med Res Opin & $41(1.4 \%)$ & UK & 2.345 & Cochrane Database Syst Rev & 2029 & UK & 7.755 \\
\hline 10 & Stat Med & $37(1.3 \%)$ & UK & 1.847 & Ann Intern Med & 1994 & USA & 19.315 \\
\hline
\end{tabular}

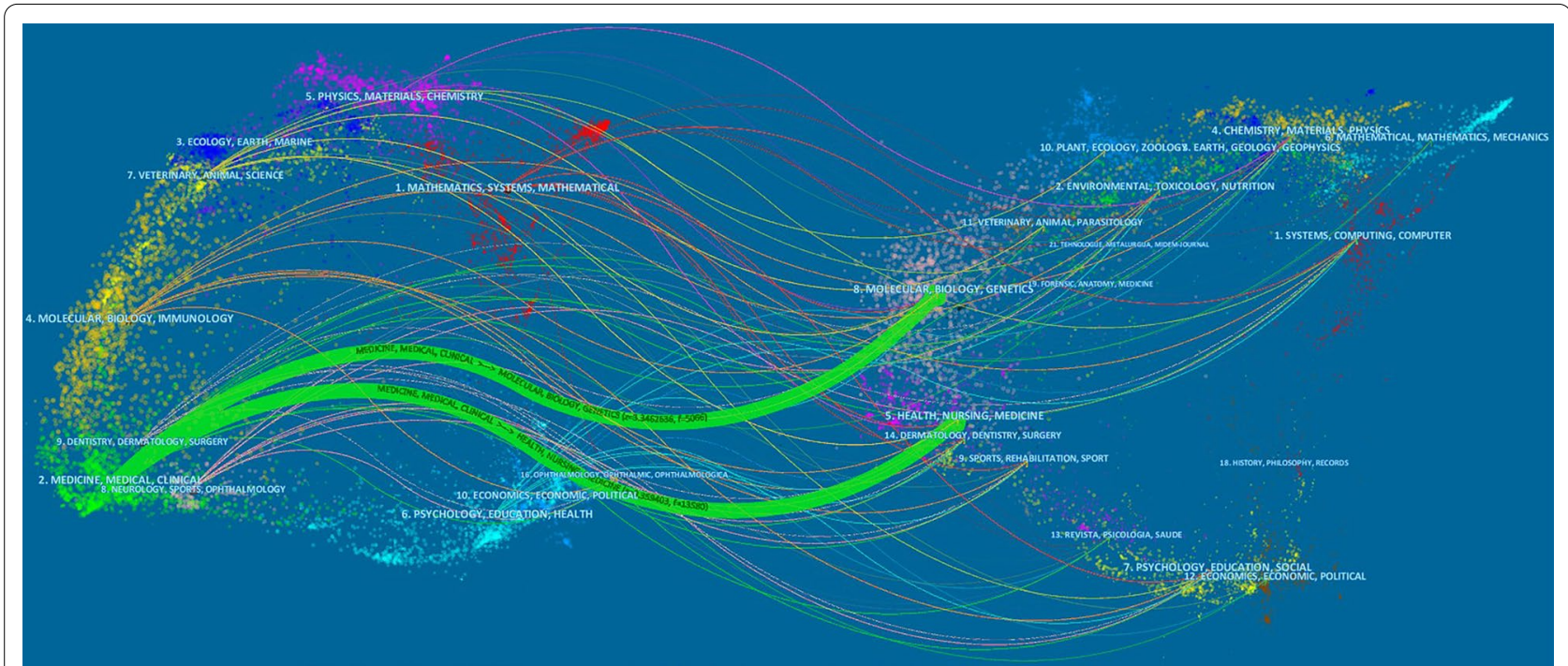

Fig. 3 The dual-map overlay of journals related to NMA research 
Table 2 The top 10 countries and institutes contributed to publications in NMA research [n (\%)]

\begin{tabular}{|c|c|c|c|c|}
\hline Rank & Country & $\mathrm{N}(\%)$ & Institute & $\mathrm{N}(\%)$ \\
\hline 1 & USA & $889(31 \%)$ & University of Bristol (UK) & $113(4.0 \%)$ \\
\hline 2 & China & $740(26 \%)$ & $\begin{array}{l}\text { University of Toronto } \\
\text { (Canada) }\end{array}$ & $106(3.7 \%)$ \\
\hline 3 & UK & 708 (25\%) & $\begin{array}{l}\text { McMaster University } \\
\text { (Canada) }\end{array}$ & $95(3.3 \%)$ \\
\hline 4 & Canada & $327(11 \%)$ & $\begin{array}{l}\text { University of loannina } \\
\text { (Greece) }\end{array}$ & $81(2.9 \%)$ \\
\hline 5 & Italy & $286(10 \%)$ & University of Oxford (UK) & $70(2.5 \%)$ \\
\hline 6 & Germany & $228(8.0 \%)$ & Columbia University (USA) & $68(2.5 \%)$ \\
\hline 7 & Switzerland & $193(6.8 \%)$ & University of York (UK) & $63(2.2 \%)$ \\
\hline 8 & Netherlands & $192(6.8 \%)$ & $\begin{array}{l}\text { University of Ottawa } \\
\text { (Canada) }\end{array}$ & $61(2.1 \%)$ \\
\hline 9 & France & $151(5.3 \%)$ & Mayo Clinic (USA) & $60(2.1 \%)$ \\
\hline 10 & Greece & $122(4.3 \%)$ & $\begin{array}{l}\text { University of Bern (Swit- } \\
\text { zerland) }\end{array}$ & $57(2.0 \%)$ \\
\hline
\end{tabular}

in the network map of the country generated by CiteSpace (Fig. 4). The top three countries in terms of centrality (purple round) were Spain (0.19), Canada (0.17), and France (0.14). In general, the cooperation between developed countries was relatively close.

3534 institutes contributed to the publications of NMA research. According to Table 2, the top five institutes were University of Bristol(113, 4.0\%), University of Toronto (106, 3.7\%), McMaster University (95, 3.3\%), University of Ioannina (81, 2.9\%), and University of Oxford (70, 2.5\%). There were 145 nodes and 467 links in the network map of the institutes generated by CiteSpace (Fig. 5). The top five institutes in terms of centrality (purple round) were Columbia University (0.23), University of Bristol (0.20), University of Ioannina (0.16), McMaster University (0.15), and University of Oxford (0.15). In general, the cooperation between institutes was relatively close.

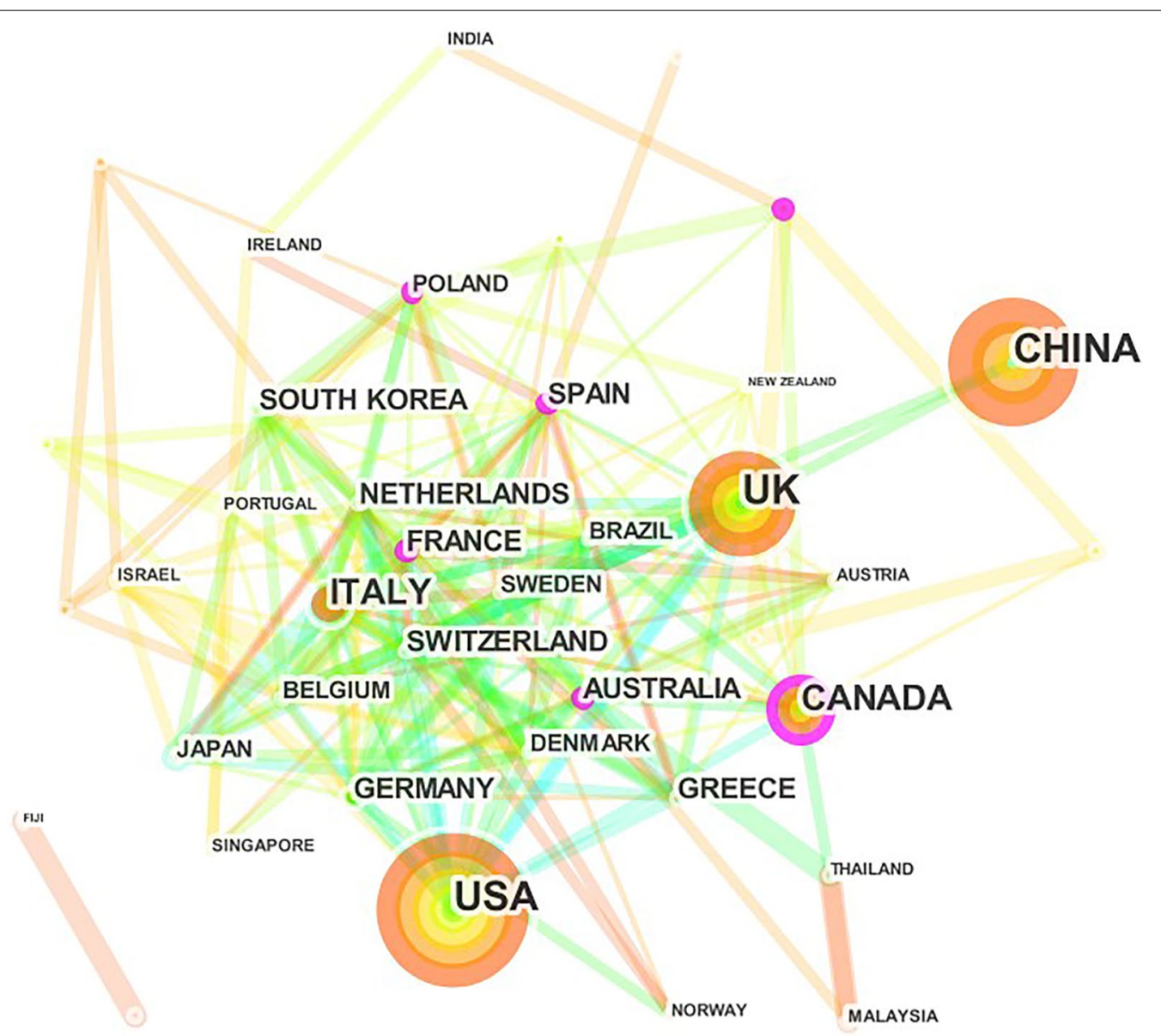

Fig. 4 The network map of countries for NMA research 


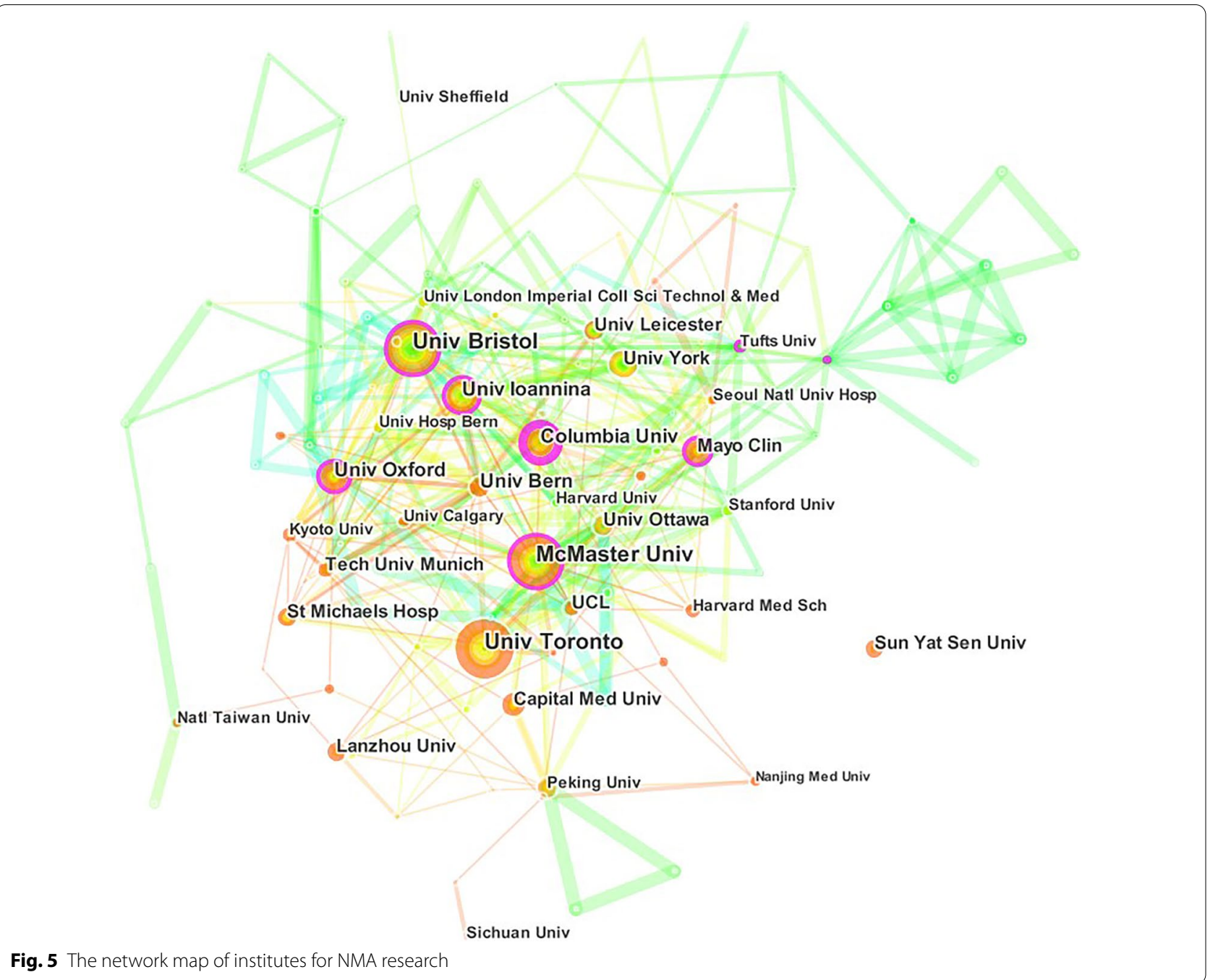

Table 3 The top 10 authors and co-cited authors in NMA research [n (\%)]

\begin{tabular}{lllll}
\hline Rank & Author & N (\%) & Co-cited Author & Citations \\
\hline 1 & Salanti G (University of Bern, Switzerland) & $67(2.4 \%)$ & Higgins JPT (University of Bristol, UK) & 1670 \\
2 & Welton NJ (University of Bristol, UK) & $47(1.7 \%)$ & Salanti G (University of Bern, Switzerland) & 1450 \\
3 & Dias S (University of Bristol, UK) & $40(1.4 \%)$ & Dias S (University of Bristol, UK) & 1279 \\
4 & Stone GW (Columbia University Medical Center, USA) & $37(1.3 \%)$ & Lu G (University of Bristol, UK) & 672 \\
5 & Ades AE (University of Bristol, UK) & $36(1.3 \%)$ & Jansen JP (Tufts University School of Medicine, USA) & 662 \\
6 & Jansen JP (Tufts University School of Medicine, USA) & $36(1.3 \%)$ & Moher D (Ottawa Hospital Research Institute, Canada) & 563 \\
7 & Biondi-Zoccai G (Sapienza University of Rome, Italy) & $35(1.2 \%)$ & Caldwell DM (University of Bristol, UK) & 530 \\
8 & Tu YK (National Taiwan University, China Taiwan) & $34(1.2 \%)$ & Palmerini T (University of Bologna, Italy) & 473 \\
9 & Cipriani A (University of Oxford, UK) & $33(1.2 \%)$ & White IR (MRC Clinical Trials Unit at UCL, UK) & 420 \\
10 & Mavridis D (University of loannina, Greece) & $32(1.1 \%)$ & Cipriani A (University of Oxford, UK) & 406 \\
\hline
\end{tabular}

\section{Authors and co-cited authors}

A total of 11,528 authors contributed to the NMA articles. Table 3 showed the top 10 authors and co-cited authors. Salanti G $(67,2.4 \%)$ from the University of Bern ranked first, followed by Welton NJ $(47,1.7 \%)$ and Dias $\mathrm{S}(40,1.4 \%)$ from the University of Bristol, and Stone 
GW from the Columbia University Medical Center (37, 1.3\%). The top five co-cited authors were Higgins JPT from University of Bristol (1670 citations), Salanti G from University of Bern (1450 citations), Dias S from University of Bristol (1279 citations), Lu G from University of Bristol (672 citations), and Jansen JP from Tufts University School of Medicine (662 citations). The remaining authors were cited times less than 600 .

\section{Co-cited references and references with citation bursts}

References with citation bursts are de-fined as those that are cited frequently over a period of time [23]. Table 4 revealed the top 10 co-cited references related to NMA research. Among them, the reference conducted by $\mathrm{Lu}$ and Ades [5] (619 co-citations) had the highest co-cited times, followed by the articles performed by Salanti et al. [27] (542 co-citations) and Caldwell et al. [8] (441 co-citations), the remaining seven references $[1,3,28-32]$ were co-cited between 300 and 380 times. Figure 6 presented the top 36 references with strong citation bursts. The first reference [1] with citation bursts appeared in 2005, and $58 \%$ of the references appeared citation bursts between 2009 and 2011.

\section{Co-occurrence keywords and cluster analysis}

A total of 10,980 keywords were identified, but 7398 (67\%) keywords appeared only one time. The keyword with the highest frequency was network meta-analysis (1424, 4.0\%), followed by randomized controlled trials $(816,2.3 \%)$, double-blind $(547,1.6 \%)$, meta-analysis (463, 1.3\%), and efficacy $(419,1.2 \%)$. The other keywords appeared less than 400 times.

Generating a keyword network map resulted in 128 nodes and 588 links (Fig. 7). All clusters were named after terms extracted from the included articles. In total, 7 clusters were identified. But cluster 4 named "multipletreatments meta-analysis" is the keyword we use when

Table 4 Top 10 co-cited references related to NMA research

\begin{tabular}{lll}
\hline Rank & Co-cited reference & Co-citation \\
\hline 1 & Lu G, 2004, STAT MED, V23, P3105 [5] & 619 \\
2 & Salanti G, 2011, J CLIN EPIDEMIOL, V64, P163 [27] & 542 \\
3 & Caldwell DM, 2005, BRIT MED J, V331, P897 [8] & 441 \\
4 & Dias S, 2010, STAT MED, V29, P932 [28] & 380 \\
5 & Higgins JPT, 2011, BMJ-BRIT MED J, V343 [29] & 351 \\
6 & Chaimani A, 2013, PLOS ONE, V8 [3] & 350 \\
7 & Salanti G, 2008, STAT METHODS MED RES, V17, P279 & 341 \\
8 & [30] & 334 \\
9 & Lumley T, 2002, STAT MED, V21, P2313 [1] & 321 \\
10 & Hutton B, 2015, ANN INTERN MED, V162, P777 [31] & 308 \\
\hline
\end{tabular}

performing the search and should be excluded. The remaining 6 clusters were named "\#0 randomized evidence", "\#1 oral anti-diabetic drug", "\#2 coronary artery bypass", “\#3 certolizumab pegol", “\#5 non valvular atrial fibrillation", and "\#6s-line antihyperglycemic therapy".

\section{Discussion}

We conducted a literature search in the Web of Science and included 2846 articles, which were published between 2002 and 2018. Before 2009, only twenty articles were published in total and the number of publications per year was less than ten, indicating that NMA research developed slowly during this period. After 2010, the annual number of publications increased rapidly, especially between 2015 and 2017. The possible reasons for the dramatic increase might be the methodology of NMA has been greatly improved; countries or regions paid more attention to this area and increased financial support; more and more people have mastered the methods of conducting NMA and started to engage in related research. More than $99 \%$ of the included NMA studies were published in English, which is related to the database mainly containing English journal articles. This may be a barrier for researchers and medical professionals who do not speak English (fluently) in accessing and/or putting out NMA publications.

2846 articles published in 771 journals, but $12 \%$ of journals published more than five papers, $68 \%$ of journals published only one paper or two papers, revealing that many journals have contributed to the publication of NMA research, but only a few journals insisted on publishing relevant research. Of the top 10 journals, seven were from the UK, and the impact factors of seven journals were lower than 4.500, indicating the journals from the UK are more often publish NMA studies, but the impact factors of these high-yield journals are not high. Of the top 10 co-cited journals, only three are also top 10 productive journals, but $70 \%$ of journals have an impact factor greater than 15.000 , which shows that the articles published in the high-impact factor journals are more often cited. Possible reason for this phenomenon may be that the high-impact journals have higher requirements on the topic selection and quality of published articles, moreover, it has higher social media dissemination and more likely to attract attention.

2846 articles involved in 3534 institutes in 85 counties. $82 \%$ of papers were published by the USA, China, and the UK, revealing that these three countries play a major role in promoting the development of NMA research. In general, the cooperation between developed countries was relatively close, but China has less cooperation with other countries, even though China had the second largest number of publications. 


\section{Top 36 References with the Strongest Citation Bursts}

\begin{tabular}{|c|c|c|c|c|c|}
\hline References & Year & Strength & Begin & End & $2002-2018$ \\
\hline LUMLEY T, 2002, STAT MED, V21, P2313, DQI & 2002 & 23.8843 & 2005 & 2010 & 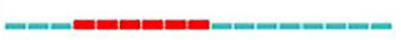 \\
\hline PSATY BN, 2003, JAMA-J AM MED ASSOC, V289, P2534, DOI & 2003 & 17.8487 & 2005 & 2011 & \\
\hline CALDWELL DM, 2005, BRIT MED J, V331, P897, DOI & 2005 & 63.4323 & 2006 & 2013 & \\
\hline LU G, 2004, STAT MED, V23, P3105, DOI & 2004 & 61.8449 & 2006 & 2012 & \\
\hline GLENNY AM, 2005, HEALTH TECHNOL ASSES, V9, P1 & 2005 & 28.1446 & 2006 & 2013 & \\
\hline COOPER NJ, 2006, ARCH INTERN MED, V166, P1269, DOI & 2006 & 13.8086 & 2007 & 2013 & \\
\hline HIGGINS JPT, 2002, STAT MED, V21, P1539, DOI & 2002 & 4.4449 & 2007 & 2009 & \\
\hline STETTLER C, 2007, LANCET, V370, P937, DOI & 2007 & 22.5332 & 2008 & 2015 & \\
\hline SONG F, 2003, BRIT MED J, V326, P472, DOI & 2003 & 8.6764 & 2008 & 2011 & \\
\hline DAEMEN J, 2007, LANCET, V369, P667, DOI & 2007 & 3.0647 & 2008 & 2010 & \\
\hline SONG F, 2008, J CLIN EPIDEMIOL, V61, P455, DOI & 2008 & 17.2894 & 2009 & 2013 & \\
\hline STETTLER C, 2008, BMJ-BRIT MED J, V337, P0, DOI & 2008 & 14.5437 & 2009 & 2013 & \\
\hline ADES AE, 2006, PHARMACOECONOMICS, V24, P1, DOI & 2006 & 11.554 & 2009 & 2012 & \\
\hline ELLIOTT WJ, 2007, LANCET, V369, P201, DOI & 2007 & 9.3587 & 2009 & 2011 & \\
\hline NIXON RM, 2007, STAT MED, V26, P1237, DOI & 2007 & 6.8162 & 2009 & 2012 & \\
\hline ADES AE, 2003, STAT MED, V22, P2995, DQI & 2003 & 5.8428 & 2009 & 2011 & \\
\hline HIGGINS JPT, 2003, BRIT MED J, V327, P557, DOI & 2003 & 5.2575 & 2009 & 2011 & \\
\hline IOANNIDIS JPA, 2006, LANCET, V368, P1470, DOI & 2006 & 3.6662 & 2009 & 2012 & \\
\hline LU GB, 2006, J AM STAT ASSOC, V101, P447, DOI & 2006 & 36.3222 & 2010 & 2014 & \\
\hline CIPRIANI A, 2009, LANCET, V373, P746, DOI & 2009 & 28.0138 & 2010 & 2015 & \\
\hline SALANTI G, 2009, J CLIN EPIDEMIOL, V62, P857, DQI & 2009 & 25.1963 & 2010 & 2014 & \\
\hline COOPER NJ, 2009, STAT MED, V28, P1861, DOI & 2009 & 22.2626 & 2010 & 2013 & \\
\hline HIGGINS JG, 2008, COCHRANE HDB SYSTEMA, V0, PO & 2008 & 18.3184 & 2010 & 2013 & \\
\hline SUTTON A, 2008, PHARMACOECONOMICS, V26, P753, DOI & 2008 & 13.7517 & 2010 & 2013 & \\
\hline LU GB, 2009, BIOSTATISTICS, V10, P792, DOI & 2009 & 11.0868 & 2010 & 2013 & \\
\hline WELTON NJ, 2009, AM J EPIDEMIOL, V169, P1158, DQI & 2009 & 7.4686 & 2010 & 2012 & \\
\hline SALANTI G, 2008, STAT METHODS MED RES, V17, P279, DOI & 2008 & 32.097 & 2011 & 2016 & \\
\hline SONG FJ, 2009, BMJ-BRIT MED J, V338, P0, DOI & 2009 & 22.8429 & 2011 & 2014 & 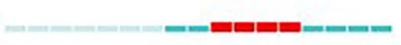 \\
\hline JANSEN JP, 2008, VALUE HEALTH, V11, P956, DOI & 2008 & 12.6864 & 2011 & 2014 & \\
\hline SALANTI G, 2008, ANN INTERN MED, V148, P544, DOI & 2008 & 10.5958 & 2011 & 2014 & \\
\hline WELLS GA, 2009, INDIRECT EVIDENCE IN, V0, P0 & 2009 & 10.2324 & 2011 & 2013 & \\
\hline DIAS S, 2011, 2 NICE DSU, v0, P0 & 2011 & 15.1507 & 2012 & 2014 & \\
\hline CUTLIP DE, 2007. CIRCULATION, V115, P2344, DOI & 2007 & 20.9627 & 2013 & 2015 & \\
\hline MILLS EJ, 2012, JAMA-J AM MED ASSOC, V308, P1246, DOI & 2012 & 12.8342 & 2014 & 2016 & $=-\boldsymbol{E}$ \\
\hline MOHER D, 2009, PLOS MED, V6, P0 & 2009 & 19.2576 & 2015 & 2018 & $=$ \\
\hline MOHER D, 2009, ANN INTERN MED, V151, P264, DOI & 2009 & 8.0977 & 2015 & 2018 & \\
\hline
\end{tabular}

Fig. 6 Top 36 references with strong citation bursts. Note The red bars mean some references cited frequently; the green bars were references cited infrequently

Therefore, China should strengthen cooperation with other countries to improve the quality and influence of NMA research. The top 10 institutes contributed to 774 papers, which accounted for $27 \%$ of the included studies. Of the top 10 institutes, 3 were from the UK, 3 from Canada, 2 from the USA, and 1 each from Greece, and Switzerland. It is worth mentioning that there were no institutes from China, Italy, Germany, Netherlands, and France among the top 10 institutes. The active collaborations were observed between the main institutes, especially between institutes from the same country. 


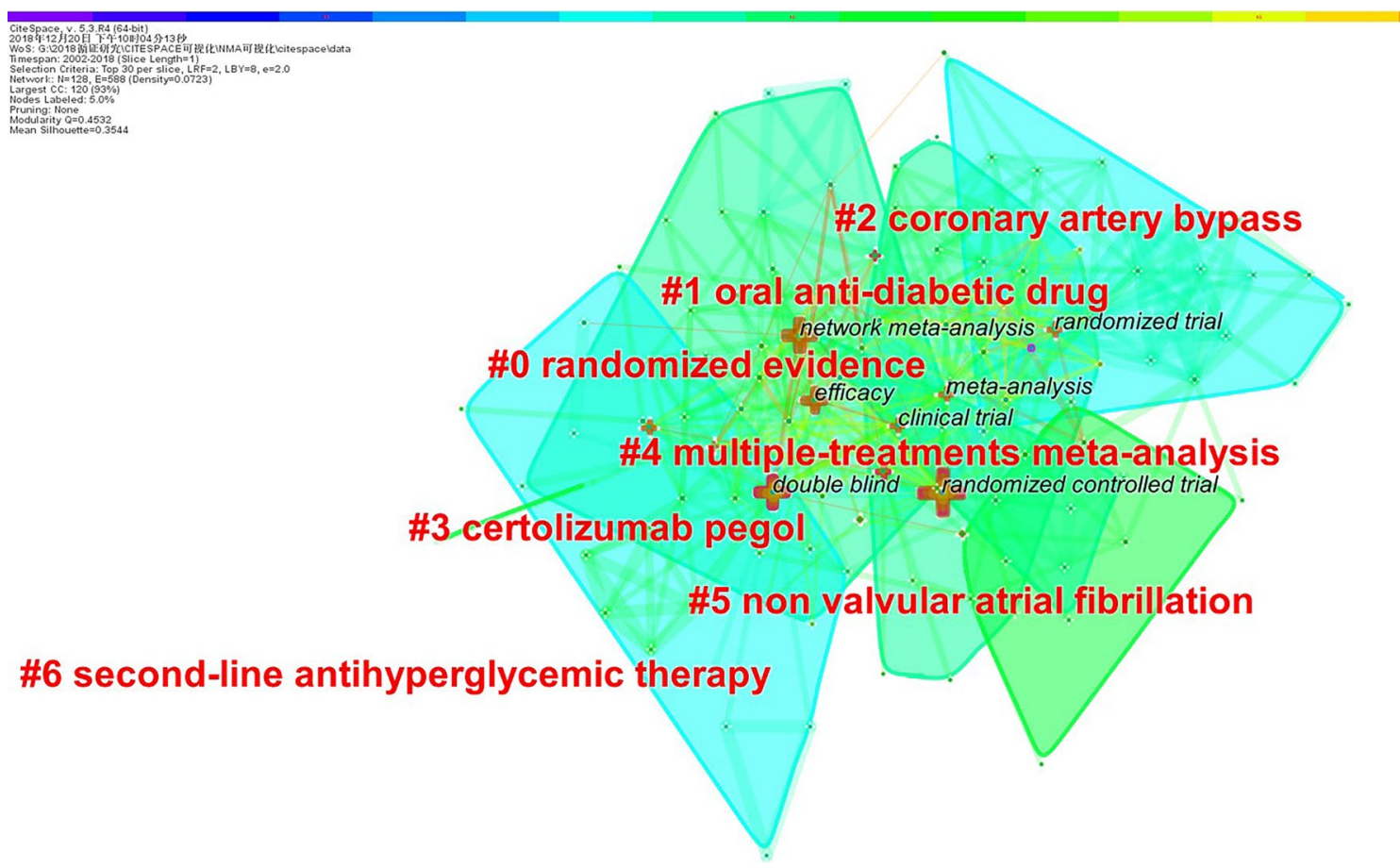

Fig. 7 The network map of keywords for NMA research

The dynamics of a field can be characterized in part by articles with citation bursts [33]. The first reference that was detected with citation burst is the study conducted by Lumley in 2002 [1], and the burst started in 2005 and ended in 2010. This article provided a new method for indirect comparisons. Among citation bursts starting in 2009 , the strongest burst is due to a 2008 paper by Song et al. [34] This study assessed the discrepancies between direct and adjusted indirect comparisons of new versus conventional pharmaceutical interventions and showed that adjusted indirect comparisons can be used to test the validity and applicability of results from head-to-head randomized trials [34], which drives the development of indirect comparisons. The strongest burst starting from 2010 is associated with a 2006 paper by Lu and Ades [35] on evidence inconsistency in mixed treatment comparisons. The authors proposed a new method for assessing evidence inconsistency in the framework of Bayesian hierarchical models. Citation bursts starting in 2011 are led by Salanti et al.s [30] article published in 2008. This methodological article focused on an important element of the NMA: network. The authors introduced the concepts of network geometry and asymmetry and proposed some methods to deal with the extent of network asymmetry [30]. The most recent strongest burst started in 2015 is associated with Moher et al. in 2009 [36]. This article presented a new reporting tool for systematic reviews called PRISMA (Preferred Reporting Items for Systematic Reviews and Meta-analyses). Subsequently, Hutton et al. [31] proposed the PRISMA extension statement based on the PRISMA in 2015, which is now widely used to assess the reporting quality of NMA.

Hotspots are scientific questions or topics discussed in a set of documents that are intrinsically linked to a certain period of time [18]. In bibliometrics, a network graph of keyword co-occurrences can reflect hot topics [22]. In the current study, we used CiteSpace V to conducted cluster analysis for keywords, and the results showed that there are 7 clusters in the field of NMA. Cluster \#0 is the largest cluster and contains 38 keywords. This cluster mainly focused on randomized evidence. Randomized controlled trials (RCTs) are considered to be the most reliable source of information on relevant treatment outcomes [37] and NMA usually only includes evidence from RCTs. When non-randomized evidence is included in the NMA, the transmission and consistency of the study are amplified, so the results may not be very accurate [38]. But in recent years, more and more NMAs have included non-randomized evidence $[39,40]$. However, randomized evidence remains the main source of evidence for NMA. Cluster \#1 includes 25 keywords and focuses on the effects of oral anti-diabetic drugs on diabetes. Cluster \#6 focuses on second-line antihyperglycemic therapy. It is estimated that more than 415 million 
adults worldwide have diabetes and the prevalence is increasing, with more than 640 million adults expected to have diabetes by 2040 [41, 42]. The risk of adverse effects of cardiovascular disease, heart failure, and kidney disease in diabetic patients is increasing [43-45], and the age of death of patients is decreasing [46, 47], which has attracted widespread attention among people in the medical and health fields. Therefore, the efficacy and adverse outcomes of various measures used for the treatment of diabetes have become one of the hot topics in NMAs. Cluster \#2 focuses on coronary artery bypass, one of the most common cardiac procedures in the world, and is the gold standard treatment for most multivessel coronary and left main coronary artery disease $[48,49]$. Cluster \#3 mainly related to certolizumab pegol, a tumor necrosis factor blocker, can be used for the treatment of rheumatoid arthritis, Crohn's disease, psoriatic arthritis, and axial spondyloarthritis [50,51]. Cluster \#5 focuses on non-valvular atrial fibrillation, a type of atrial fibrillation that occurs without a mechanical prosthetic heart valve and moderate to severe mitral stenosis [52]. In general, the main hot topics covered by NMA are the treatment of diabetes, cardiovascular diseases, and immune rheumatism.

\section{Strengths and limitations}

As far as we know, this is the first study to perform a bibliometric analysis of NMA research by using CiteSpace and HistCite. In addition to analyzing the social network relationships of institutions and countries, we also carried out cluster analysis of keywords and detection of burst references, which can clearly show the hot topics and development trends of NMA. But our study also has some limitations. First, we only included the NMA articles published in the WoS database, which may not fully reflect the current status of all NMA research, although WoS is considered to be the most important data source for bibliometric analysis in science [11]. Second, almost all of the included studies are in English, which may lead to selection bias. Therefore, the results may not be applicable to NMAs published in other languages [19]. Third, there are some inconsistencies in the data analysis process, such as one author from different units, one organization with different names, and the same meaning keywords have different expressions. Although we have standardized the authors, institutions, and keywords in our research, potential errors may still exist.

\section{Conclusions}

NMA studies have significantly increased over the past decade, especially from 2015 to 2017. Worldwide, researchers in the field come mostly from Western Europe and North America, mainly spread in the USA,
China, and UK. There were active collaborations between developed countries, it is suggested that cooperation should be strengthened between developed countries and developing counties in the future. The University of Bristol, University of Toronto, and McMaster University were the top three most productive institutes. The active collaborations were observed between the main institutes, especially between institutes from the same country. There were seven hot topics. The treatment of diabetes, cardiovascular diseases, and immune rheumatism may be the main hot topics.

\section{Abbreviations}

NMA: Network meta-analysis; RCTs: Randomized controlled trials.

\section{Acknowledgements}

The authors thank all investigators and supporters involved in this study.

\section{Authors' contributions}

JS, YG, ML and JT planned and designed the study. YG and JT developed the search strategies. YG, ML, KY, YS, JC, SS, JS, and JG performed the statistical analysis. LL, JW, and JT conducted arbitration under disagreement and ensured that there were no errors. JS, YG, and JT wrote the first draft. JS, YG, $\mathrm{LL}$, and JT revised the draft. All authors approved the final version of the manuscript.

\section{Funding}

Science and Technology Planning Project of Gansu Province (Project Number: 20CX4ZA027); Science and Technology Planning Project of Gansu Province (Project Number: 20CX9ZA112).

\section{Availability of data and materials}

All data generated or analyzed during this study are included in this published article.

\section{Declarations}

Ethics approval and consent to participate Not applicable.

\section{Consent for publication}

Not applicable.

\section{Competing interests}

The authors declare that they have no competing interests.

\section{Author details}

${ }^{1}$ Evidence-Based Nursing Centre, School of Nursing, Lanzhou University, Lanzhou City, China. ${ }^{2}$ Evidence-Based Medicine Center, School of Basic Medical Sciences, Lanzhou University, Lanzhou City, China. ${ }^{3}$ School of Nursing, Peking University, Beijing City, China. ${ }^{4}$ Mianyang hospital of traditional Chinese medicine, Mianyang City, China. ${ }^{5}$ Department of General Surgery, The Second Hospital of Lanzhou University, Lanzhou City, China. ${ }^{6}$ Second Xiangya Hospital, Central South University, Changsha City, China. ${ }^{7}$ Department of Clinical Chinese Pharmacy, School of Chinese Materia Medica, Beijing University of Chinese Medicine, Beijing City, China. ${ }^{8}$ Key Laboratory of Evidence-Based Medicine and Knowledge Translation of Gansu Province, Lanzhou City, China.

Received: 26 January 2020 Accepted: 10 March 2021

Published online: 03 May 2021 


\section{References}

1. Lumley T. Network meta-analysis for indirect treatment comparisons. Stat Med. 2002:21(16):2313-24.

2. Zhao H, Hodges JS, Ma H, Jiang Q, Carlin BP. Hierarchical Bayesian approaches for detecting inconsistency in network meta-analysis. Stat Med. 2016;35(20):3524-36

3. Gao Y, Ge L, Ma X, Shen X, Liu M, Tian J. Improvement needed in the network geometry and inconsistency of Cochrane network meta-analyses: a cross-sectional survey. J Clin Epidemiol. 2019;113:214-27.

4. Li L, Tian J, Tian H, Moher D, Liang F, Jiang T, Yao L, Yang K. Network metaanalyses could be improved by searching more sources and by involving a librarian. J Clin Epidemiol. 2014;67(9):1001-7.

5. Lu G, Ades AE. Combination of direct and indirect evidence in mixed treatment comparisons. Stat Med. 2004;23(20):3105-24

6. Mavridis D, Giannatsi M, Cipriani A, Salanti G. A primer on network meta-analysis with emphasis on mental health. Evid Based Ment Health. 2015;18(2):40-6.

7. Noma H, Tanaka S, Matsui S, Cipriani A, Furukawa TA. Quantifying indirect evidence in network meta-analysis. Stat Med. 2017;36(6):917-27.

8. Caldwell DM, Ades AE, Higgins JP. Simultaneous comparison of multiple treatments: combining direct and indirect evidence. BMJ (Clin Res Ed) 2005;331(7521):897-900.

9. Li T, Puhan MA, Vedula SS, Singh S, Dickersin K. Network meta-analysishighly attractive but more methodological research is needed. BMC Med. 2011;9:79.

10. Achana FA, Cooper NJ, Dias S, Lu G, Rice SJ, Kendrick D, Sutton AJ. Extending methods for investigating the relationship between treatment effect and baseline risk from pairwise meta-analysis to network meta-analysis. Stat Med. 2013;32(5):752-71

11. Chen $H$, Jiang W, Yang $Y$, Yang $Y$, Man X. Global trends of municipal solid waste research from 1997 to 2014 using bibliometric analysis. J Air Waste Manag Assoc (1995). 2015;65(10):1161-70.

12. Chen D, Liu Z, Luo ZH, Webber M, Chen J. Bibliometric and visualized analysis of emergy research. Ecol Eng. 2016;90:285-93.

13. Li W, Zhao Y. Bibliometric analysis of global environmental assessment research in a 20-year period. Environ Impact Assess Rev. 2015;50:158-66.

14. Miao Y, Zhang Y, Yin L. Trends in hepatocellular carcinoma research from 2008 to 2017: a bibliometric analysis. PeerJ. 2018;6:e5477.

15. Li C, Wu K, Wu J. A bibliometric analysis of research on haze during 2000-2016. Environ Sci Pollut Res. 2017;24(32):24733-42.

16. Ruiz-Real JL, Uribe-Toril J, Valenciano JP, Gazquez-Abad JC. Worldwide research on circular economy and environment: a bibliometric analysis. Int J Environ Res Public Health. 2018;15(12):2699.

17. Gimenez-Espert MDC, Prado-Gasco VJ. Bibliometric analysis of six nursing journals from the Web of Science, 2012-2017. J Adv Nurs. 2018;75:543-54

18. Liang C, Luo A, Zhong Z. Knowledge mapping of medication literacy study: a visualized analysis using CiteSpace. SAGE Open Med. 2018:6:2050312118800199.

19. Li L, Catala-Lopez F, Alonso-Arroyo A, Tian J, Aleixandre-Benavent R, Pieper D, Ge L, Yao L, Wang Q, Yang K. The global research collaboration of network meta-analysis: a social network analysis. PLOS ONE. 2016:11(9):e0163239.

20. Zhang M, Gao M, Yue S, Zheng T, Gao Z, Ma X, Wang Q. Global trends and future prospects of food waste research: a bibliometric analysis. Environ Sci Pollut Res Int. 2018;25(25):24600-10.

21. Chen CM. CiteSpace II: Detecting and visualizing emerging trends and transient patterns in scientific literature. J Am Soc Inf Sci Technol. 2006;57(3):359-77.

22. Liang YD, Li Y, Zhao J, Wang XY, Zhu HZ, Chen XH. Study of acupuncture for low back pain in recent 20 years: a bibliometric analysis via CiteSpace. J Pain Res. 2017:10:951-64.

23. Gao Y, Shi S, Ma W, Chen J, Cai Y, Ge L, Li L, Wu J, Tian J. Bibliometric analysis of global research on PD-1 and PD-L1 in the field of cancer. Int Immunopharmacol. 2019;72:374-84.

24. Gao Y, Ge L, Shi S, Sun Y, Liu M, Wang B, Shang Y, Wu J, Tian J. Global trends and future prospects of e-waste research: a bibliometric analysis. Environ Sci Pollut Res Int. 2019;26(17):17809-20.

25. Xie P. Study of international anticancer research trends via co-word and document co-citation visualization analysis. Scientometrics. 2015:105(1):611-22
26. Chen CM, Leydesdorff L. Patterns of connections and movements in dual-map overlays: a new method of publication portfolio analysis. J Am Soc Inf Sci. 2014;65(2):334-51.

27. Salanti G, Ades AE, loannidis JP. Graphical methods and numerical summaries for presenting results from multiple-treatment meta-analysis: an overview and tutorial. J Clin Epidemiol. 2011;64(2):163-71.

28. Dias S, Welton NJ, Caldwell DM, Ades AE. Checking consistency in mixed treatment comparison meta-analysis. Stat Med. 2010;29(7-8):932-44.

29. Higgins JP, Altman DG, Gotzsche PC, Juni P, Moher D, Oxman AD, Savovic J, Schulz KF, Weeks L, Sterne JA. The Cochrane Collaboration's tool for assessing risk of bias in randomised trials. BMJ (Clin Res Ed). 2011;343:d5928.

30. Salanti G, Higgins JP, Ades AE, loannidis JP. Evaluation of networks of randomized trials. Stat Methods Med Res. 2008;17(3):279-301.

31. Hutton B, Salanti G, Caldwell DM, Chaimani A, Schmid CH, Cameron C, loannidis JP, Straus S, Thorlund K, Jansen JP, et al. The PRISMA extension statement for reporting of systematic reviews incorporating network meta-analyses of health care interventions: checklist and explanations. Ann Intern Med. 2015;162(11):777-84.

32. Higgins JP, Thompson SG, Deeks JJ, Altman DG. Measuring inconsistency in meta-analyses. BMJ (Clin Res Ed). 2003;327(7414):557-60.

33. Chen C, Dubin R, Kim MC. Orphan drugs and rare diseases: a scientometric review (2000-2014). Expert Opin Orphan Drugs. 2014;2(7):709-24.

34. Song F, Harvey I, Lilford R. Adjusted indirect comparison may be less biased than direct comparison for evaluating new pharmaceutical interventions. J Clin Epidemiol. 2008;61(5):455-63.

35. Lu GB, Ades AE. Assessing evidence inconsistency in mixed treatment comparisons. J Am Stat Assoc. 2006;101(474):447-59.

36. Moher D, Liberati A, Tetzlaff J, Altman DG. Preferred reporting items for systematic reviews and meta-analyses: the PRISMA statement. PLoS Med. 2009:6(7):e1000097.

37. Rothwell PM. External validity of randomised controlled trials: "to whom do the results of this trial apply?" Lancet (London, England). 2005;365(9453):82-93.

38. Efthimiou O, Mavridis D, Debray TP, Samara M, Belger M, Siontis GC, Leucht S, Salanti G. Combining randomized and non-randomized evidence in network meta-analysis. Stat Med. 2017;36(8):1210-26.

39. Schunemann HJ, Tugwell P, Reeves BC, AkI EA, Santesso N, Spencer FA, Shea B, Wells G, Helfand M. Non-randomized studies as a source of complementary, sequential or replacement evidence for randomized controlled trials in systematic reviews on the effects of interventions. Res Synth Methods. 2013:4(1):49-62.

40. Cameron C, Fireman B, Hutton B, Clifford T, Coyle D, Wells G, Dormuth $\mathrm{CR}$, Platt $\mathrm{R}$, Toh S. Network meta-analysis incorporating randomized controlled trials and non-randomized comparative cohort studies for assessing the safety and effectiveness of medical treatments: challenges and opportunities. Syst Rev. 2015;4:147.

41. Ogurtsova K, da Rocha Fernandes JD, Huang Y, Linnenkamp U, Guariguata L, Cho NH, Cavan D, Shaw JE, Makaroff LE. IDF Diabetes Atlas: global estimates for the prevalence of diabetes for 2015 and 2040. Diabetes Res Clin Pract. 2017:128:40-50.

42. Wiviott SD, Raz I, Bonaca MP, Mosenzon O, Kato ET, Cahn A, Silverman MG, Zelniker TA, Kuder JF, Murphy SA, et al. Dapagliflozin and cardiovascular outcomes in type 2 diabetes. N Engl J Med. 2018;380:347-57.

43. Roger VL, Go AS, Lloyd-Jones DM, Benjamin EJ, Berry JD, Borden WB, Bravata DM, Dai S, Ford ES, Fox CS, et al. Heart disease and stroke statistics - 2012 update: a report from the American Heart Association. Circulation. 2012;125(1):e2-220.

44. Ahmad FS, Ning H, Rich JD, Yancy CW, Lloyd-Jones DM, Wilkins JT. Hypertension, obesity, diabetes, and heart failure-free survival: the Cardiovascular Disease Lifetime Risk Pooling Project. JACC Heart Fail. 2016:4(12):911-9.

45. Wanner C, Inzucchi SE, Lachin JM, Fitchett D, von Eynatten M, Mattheus M, Johansen OE, Woerle HJ, Broedl UC, Zinman B. Empagliflozin and progression of kidney disease in type 2 diabetes. N Engl J Med. 2016:375(4):323-34.

46. Lind M, Garcia-Rodriguez LA, Booth GL, Cea-Soriano L, Shah BR, Ekeroth G, Lipscombe LL. Mortality trends in patients with and without diabetes in Ontario, Canada and the UK from 1996 to 2009: a population-based study. Diabetologia. 2013;56(12):2601-8. 
47. Kennon B, Leese GP, Cochrane L, Colhoun H, Wild S, Stang D, Sattar N, Pearson D, Lindsay RS, Morris AD, et al. Reduced incidence of lowerextremity amputations in people with diabetes in Scotland: a nationwide study. Diabetes Care. 2012;35(12):2588-90.

48. Mounsey CA, Mawhinney JA, Werner RS, Taggart DP. Does previous transradial catheterization preclude use of the radial artery as a conduit in coronary artery bypass surgery? Circulation. 2016;134(9):681-8.

49. Benedetto U, Gaudino M, Ng C, Biondi-Zoccai G, D'Ascenzo F, Frati G, Girardi LN, Angelini GD, Taggart DP. Coronary surgery is superior to drug eluting stents in multivessel disease. Systematic review and metaanalysis of contemporary randomized controlled trials. Int J Cardiol. 2016;210:19-24

50. Campanati A, Benfaremo D, Luchetti MM, Ganzetti G, Gabrielli A, Offidani A. Certolizumab pegol for the treatment of psoriasis. Expert Opin Biol Ther. 2017;17(3):387-94
51. Desmarais J, Beier S, Deodhar A. Certolizumab pegol for treating axial spondyloarthritis. Expert Opin Biol Ther. 2016;16(8):1059-64.

52. Heidbuchel $\mathrm{H}$, Verhamme P, Alings $M$, Antz M, Diener HC, Hacke W, Oldgren J, Sinnaeve P, Camm AJ, Kirchhof P. Updated European Heart Rhythm Association practical guide on the use of non-vitamin-K antagonist anticoagulants in patients with non-valvular atrial fibrillation: executive summary. Eur Heart J. 2017;38(27):2137-49.

\section{Publisher's Note}

Springer Nature remains neutral with regard to jurisdictional claims in published maps and institutional affiliations.
Ready to submit your research? Choose BMC and benefit from:

- fast, convenient online submission

- thorough peer review by experienced researchers in your field

- rapid publication on acceptance

- support for research data, including large and complex data types

- gold Open Access which fosters wider collaboration and increased citations

- maximum visibility for your research: over $100 \mathrm{M}$ website views per year

At BMC, research is always in progress.

Learn more biomedcentral.com/submissions 